\title{
Effects of polystyrene microplastics on early stages of two marine invertebrates with different feeding strategies ${ }^{\text {th }}$
}

\author{
Silvia Messinetti, Silvia Mercurio*, Marco Parolini, Michela Sugni, Roberta Pennati \\ Department of Environmental Science and Policy, Università degli Studi di Milano, Via Celoria 26, 20133 Milano, Italy
}

A R T I C LE INFO

Article history:

Received 11 September 2017

Received in revised form 7 November 2017

Accepted 7 November 2017

Available online $\mathrm{xxx}$

Keywords

Microplastic

Polystyrene

Ciona robusta

Ingestion rate

Paracentrotus lividus

\begin{abstract}
A B S T R A C T
Nowadays, microplastics represent one of the main threats to marine ecosystems, being able to affect organisms at different stages of their life cycle and at different levels of the food web. Although the presence of plastic debris has been reported in different habitats and the ability to ingest it has been confirmed for different taxa, few studies have been performed to elucidate the effects on survival and development of marine animals. Thus, we explored the effects of different environmental concentrations of polystyrene microbeads on the early stages of two invertebrate species widespread in the Mediterranean shallow waters: the pelagic planktotrophic pluteus larvae of the sea urchin Paracentrotus lividus and the filter-feeding sessile juveniles of the ascidian Ciona robusta. We evaluated the effects on larvae and juvenile development and determined the efficiency of bead ingestion. The feeding stages of both species proved to be extremely efficient in ingesting microplastics. In the presence of microbeads, the metamorphosis of ascidian juveniles was slowed down and development of plutei altered. These results prompted the necessity to monitor the populations of coastal invertebrates since microplastics affect sensitive stages of life cycles and may have consequences on generation recruitment.

Polystyrene microplastics can alter sensitive developmental stages of marine invertebrates, being filter-feeding organisms more effective in ingesting plastic particles.
\end{abstract}

(C) 2017

\section{Introduction}

Microplastics (MPs) are small plastic particles $(1 \mu \mathrm{m}-1 \mathrm{~mm}$; Andrady, 2015) some of which are specifically produced at the micro-level scale, such as sandblasting media, virgin pellet, cosmetics (Fendall and Sewell, 2009), while others originate from the degradation of bigger plastic debris, such as polyester fibers, polyethylene plastic bags and polystyrene particles from buoys and floats (Browne et al., 2011; Davidson, 2012; O'Brine and Thompson, 2010).

Over the past 50 years, an incredible amount of plastic has reached the marine environment and its presence has been recorded in different aquatic habitats at all latitudes (Thompson et al., 2004). The potential negative impact of this big debris on the ecosystems has been taken into consideration since the 1980s (Stefatos et al., 1999) while the MPs have been neglected until recent time, when numerous studies flourished, highlighting the presence of these particles in different environmental compartments. In North American Great Lakes, 43,000 microplastic particles $/ \mathrm{km}^{2}$ have been registered (Eriksen et al., 2013), whereas the sediments of Italian Garda Lake contain more than 1000 particles $/ \mathrm{m}^{2}$ (Imhof et al., 2013). According to Eriksen et al. (2014) there are over 5 trillion microplastics floating in the oceans. More in detail, their amount in the coastal waters has

\footnotetext{
? This paper has been recommended for acceptance by Dr. Harmon Sarah Michele.

* Corresponding author.

Email address: sil.mercurio@gmail.com (S. Mercurio)
}

been estimated to vary from 3 to 100,000 item $/ \mathrm{m}^{3}$ (Carpenter et al., 1972; Doyle et al., 2011; Noren and Naustvoll, 2010) and to exceed 67,000 particles $/ \mathrm{km}^{2}$ in the open oceans (Colton et al., 1974). However, this measurement has been determined through the employment of plankton nets that have a mesh size between 80 and $330 \mu \mathrm{m}$, generating an important underestimation of the abundance and distribution of the smaller particles, which probably represent the highest threat (Andrady, 2015). Moreover, the influence of tide, wind, wave action and oceans currents determines a high variability of spatial and temporal distribution of particles, making extremely difficult a real quantification of MPs abundance.

Nowadays, the ecological impacts of MPs are of particular interest but our knowledge about their effects on marine organisms is still very limited. MPs ingestion has been demonstrated in different taxa including fish (Boerger et al., 2010; Davison and Asch, 2011; Lusher et al., 2012), seabirds (van Franeker et al., 2011), benthic polychaetes (Wright et al., 2013), amphipods, lugworms, barnacles (Thompson et al., 2004), mussels (Browne et al., 2008), decapod crustaceans (Murray and Cowie, 2011) and in different zooplanktonic organisms (Cole et al., 2013). The negative effects of MPs oral uptake vary from damaging and blocking the feeding appendages and digestive system (Derraik, 2002; Laist, 1997; Murray and Cowie, 2011), to limiting the food intake and transferring pollutants in living organisms (Mato et al., 2001; Oehlmann et al., 2009; Talsness et al., 2009; Teuten et al., 2009). In copepods, the co-presence of MPs beads and algae reduces the ingestion rate of the latter (Cole et al., 2013) and ultimately causes fertility reduction, probably due to insufficient nutrition (Lee 
et al., 2013). However, other species, such as polychaete worms, are able to ingest and expel plastic microspheres without any apparent detrimental effects, underlying the variety of responses in the different taxa (Cole et al., 2011).

When MPs reach the marine environment, they can interact with a wide range of organisms (Barnes et al., 2009). Animals inhabiting different compartments of the marine environment and displaying different feeding strategies can be differently affected by MPs. Moreover, different stages of the life cycle can have diverse sensitiveness, being the larvae usually the most vulnerable.

Very scant data are available regarding the effects of MPs on the development of aquatic organisms, as most studies have focused on the chemical aspects of MPs. In fact, the toxic effects of leachate from particles have been analyzed in different organisms, such as mussels (Gandara e Silva et al., 2016), fish (Lonnstedt and Eklov, 2016) and sea urchins (Nobre et al., 2015), whereas the physical effects are still scarcely explored (Kaposi et al., 2013).

To fill this important gap of knowledge, we evaluated the effects of environmental MPs concentrations on developmental stages of two different invertebrate species. Ciona robusta (Brunetti et al., 2015; Pennati et al., 2015) is a solitary ascidian, inhabiting shallow waters, in particular coastal areas rich of organic material (Satoh, 1994), and proposed as model organism to test water pollution (Zega et al., 2009). The adults develop through tadpole non-feeding larvae which swim for few hours before adhering to a substrate and metamorphosing into sessile juveniles (Chiba et al., 2004; Hotta et al., 2007). Both ascidian adults and juveniles are filter feeding and exploit the pharyngeal gill slits in muco-ciliary plankton feeding (Burighel and Cloney, 1997). Paracentrotus lividus is a common echinoid of the Mediterranean and North Atlantic coasts. This herbivorous sea urchin has an important role in coastal ecosystem maintenance as its foraging activity remarkably affects the compositions and the dynamics of algal and rocky littoral pools (Lawrence, 1975). Mature gametes are released directly in sea water and the larvae are pelagic until they become competent and undergo metamorphosis after about three weeks. Feeding activity starts slightly before the pluteus stage is reached, $48 \mathrm{~h}$ post fertilization (Giudice, 1986). The larvae feed on plankton employing external ciliary bands (Strathmann, 1971).

The chosen species offered the unique opportunity to evaluate and compare the impact of MPs on the development of two different suspension feeders: the pelagic suspension feeding plutei and the sessile filter-feeding ascidian juveniles. These allowed us to investigate if MPs differently affect animals with different feeding strategies. This information is of key importance to evaluate the existence of a specific sensitive compartment in the marine environment and properly manage its natural resources.

\section{Materials and methods}

\subsection{Microplastics}

Polystyrene spherical microparticles with a dark red color and a diameter of $10 \mu \mathrm{m}$ were used in the experiments; chemical and physical properties of the MPs were provided by the supplier (Sigma, Italy). The red color allowed us to follow the beads track inside the transparent tested animals. The size of microbeads was chosen to be compatible with the plutei mouth opening (about $20 \mu \mathrm{m}$ ) and ascidian juvenile oesophagus $(20-30 \mu \mathrm{m})$. Polystyrene microbeads were preferred because, unlike other plastics, they have a negligible styrene release in suspension (Cohen et al., 2002), ensuring that the observed effects can be ascribed to the physical presence of plastic particles and not to monomer contamination. The commercial standard was an aqueous suspension with a particle concentration of $50 \mathrm{mg} / \mathrm{ml}$, that was diluted 1:1000 in artificial sea water buffered with $5 \mathrm{mM}$ Hepes $\mathrm{pH} 8$ (ASWH) to produce a stock suspension of $50 \mu \mathrm{g} / \mathrm{ml}$ of beads from which the final exposure suspensions were made. As published protocols suggested (Cole et al., 2013; Kaposi et al., 2013), all the suspensions were freshly prepared every time and sonicated for $10 \mathrm{~min}$ before use to ensure a homogenous distribution of the beads in the medium. Based on previous works (Lee et al., 2013), four different microparticles concentrations were tested: $0.125,1.25,12.5$ and $25 \mu \mathrm{g} / \mathrm{ml}$.

For both the experimental models, all the experiments were performed in triplicate.

\subsection{Ascidians}

Adults of the ascidian C. robusta were collected from natural populations in Chioggia bay (Venice, Italy) and maintained in aquaria at $18 \pm 1{ }^{\circ} \mathrm{C}$. Constant light condition was preferred to promote gamete production and avoid spawning (Lambert and Brandt, 1967). For each experiment, at least three adults were sacrificed. Eggs and sperms were obtained by dissection of gonoducts and cross fertilization was performed in vitro. Embryos were cultured at $18 \pm 1{ }^{\circ} \mathrm{C}$ in ASWH until they reached the desired developmental stages (see below).

\subsubsection{Development and larval survival rate}

To test the effects of MPs presence on ascidian embryonic development, 30 embryos at 2-cells stage were exposed to the different bead concentrations in ASWH. Each exposure was performed in triplicate $(\mathrm{n}=450)$. They were reared at $18 \pm 1{ }^{\circ} \mathrm{C}$ until control larvae $(\mathrm{CO})$, maintained in ASWH, reached the hatching larva stage $(-18 \mathrm{~h}$ post fertilization (hpf); Hotta et al., 2007). To keep MPs in suspension, embryos were maintained in gently rocking condition. After $-18 \mathrm{hpf}$, the survival rate was evaluated: each experimental group was carefully observed under a stereoscope and the percentage of alive larvae was calculated as: (number of alive larvae/total exposed embryos) x 100 . Subsequently, larvae were fixed in $4 \%$ paraformaldehyde in standard Phosphate buffer saline (PBS) supplemented with $0.5 \mathrm{M} \mathrm{NaCl}$, for $1.5 \mathrm{~h}$ at room temperature. After a few washes in PBT (PBS $+0.01 \%$ Tween 20), larvae were mounted on slides and observed under a dissection microscope to evaluate the presence of malformations.

\subsubsection{Metamorphosis}

Ascidian embryos develop into tadpole swimming larvae that, after few hours, metamorphose into sessile juveniles, in which adult tissues and organs differentiate. To determine the effects of MPs on metamorphosis, embryos were allowed to develop in ASWH until they reached the hatching larva stage. Then, 30 larvae for each treatment were transferred into $5.5 \mathrm{~cm}$ Petri dishes and allow to attach to the substrate. After adhesion, ASWH was replaced with the testing suspensions $(0.125,1.25,12.5$ and $25 \mu \mathrm{g} / \mathrm{ml}$ microbeads in ASWH). Control animals (CO) were maintained in fresh ASWH. $100 \mu \mathrm{l}$ of a concentrated suspension of algae (Tetraselmis sp. 4-10 $\mu \mathrm{m}$ of diameter) were added to each treatment. The media were changed every day with freshly prepared ones. Animals were left to develop in the experimental conditions for four days. Then, each individual was observed under a stereoscope to estimate the proceeding of juvenile development. Each treatment was performed in triplicate $(n=90)$. The metamorphosis in C. robusta is a complex series of events (Chiba et al., 2004), mainly consisting in tail reabsorption, organs rotation and development of protostigmata or gill slits. By day 4 , juveniles nor- 
mally reach stage 4 , characterized by completed organs rotation and the presence of two pairs of protostigmata (for a comprehensive description of Ciona metamorphosis process see Chiba et al., 2004). To evaluate MPs effects on metamorphosis and juvenile development, we assigned a developmental stage, roughly corresponding to those described in Chiba et al. (2004), to each individuals, mainly evaluating organs rotation and the dimension of the axial complex. Stage 4 juveniles had a small almost negligible axial complex; stage 3 juveniles had completed organ rotation but retained a big axial complex; stage 2 samples did not start the organs rotation. Moreover, we counted animals that had adhered to the dish and died soon after (Fig. 1A-D).

\subsubsection{Juvenile survival}

Effects on juvenile survival were evaluated exposing -90 metamorphosed individuals (30 for each replica) at stage 3 to the different concentrations of MPs for 8 days. Stage 3 was chosen since it was the stage just before the oral siphon started contracting (Chiba et al., 2004). The suspensions were supplemented with $100 \mu$ of concentrated algae and renewed every day with freshly prepared ones. A control group (CO) was reared in ASWH plus algae. Then, each individual was observed under a stereoscope and the percentage of alive juveniles was recorded.

\subsubsection{Feeding behaviour and ingestion rates}

To measure the ingestion rate, 30 juveniles at stage 4 (Chiba et al., 2004) were exposed to MPs. As soon as the exposure suspensions were added, the single individuals were observed under a stereoscope and the feeding activity was recorded for $1 \mathrm{~min}$ using a Leica DFC-450-C camera. The ingestion rate was calculated as the number of particles ingested in the first minute of exposure. The juveniles were maintained in the exposure media for $12 \mathrm{~h}$ then the suspensions were replaced with ASWH plus algae. After $24 \mathrm{~h}$, the percentage of juveniles with MPs in their digestive tract and/or in faecal pellets was calculated to estimate the expelling efficiency.

\subsection{Sea urchins}

Adults of Paracentrotus lividus were collected in the Gulf of Lerici (La Spezia, Italy) and reared in aquaria as previously described (Mercurio et al., 2014). Gametes were obtained by intraoral injection of 1-2 ml of $1 \mathrm{M} \mathrm{KCl}$ (Kaposi et al., 2013) from adults of homogenous size $(\varnothing \sim 4 \mathrm{~cm})$. Fertilization and embryos culture were performed at $18^{\circ} \mathrm{C}$ with $12 \mathrm{~h}$ dark/light cycle in $300 \mathrm{ml}$ of gently aerated ASWH. As sea urchin larvae start eating between 36 and $48 \mathrm{~h}$ post fertilization (hpf), Phyto Reef (SHG, Italy), a nutritional supplement based on microalgae $(2-8 \mu \mathrm{m})$ was added to the media just before feeding activity began.

\subsubsection{Development and larval survival rate}

Sea urchin embryos were allowed to develop in ASWH for $24 \mathrm{hpf}$. Then, $25 \mathrm{ml}$ of ASWH with embryos were added to $25 \mathrm{ml}$ of MPs suspensions in order to reach the final testing concentrations $(0.125$, $1.25,12.5$ and $25 \mu \mathrm{g} / \mathrm{ml}$ microbeads in ASWH $+\mathrm{CO})$. When the larvae reached the 4-armed pluteus stage ( $72 \mathrm{hpf}), 1 \mathrm{ml}$ of each treatment suspension plus plutei was collected and the percentage of alive larvae was evaluated under a microscope as: (number of larvae with ciliary movements/total number of larvae) x 100 . To assess the effects on development, a further $1 \mathrm{ml}$ of each suspension was collected and larvae were fixed in $4 \%$ paraformaldehyde in PBS supplemented with $0.5 \mathrm{M}$ $\mathrm{NaCl} .90$ randomly chosen animals for each tested concentration were photographed under an optical microscope and body length, post-oral arm length and body width (Fig. 3A) were measured to verify the presence of developmental delay or malformations as reported by Kaposi and collaborators (2013).

\subsection{Comparison between ascidian and sea urchin feeding activity}

To compare the ingestion efficiency of ascidian filter-feeding juveniles and sea urchin pelagic plutei, we exposed for an hour stage 4 juveniles and 72 hpf plutei to the different concentrations of MPs. Subsequently, juveniles and plutei were observed under a stereomicroscope and number of individuals displaying MPs in their digestive
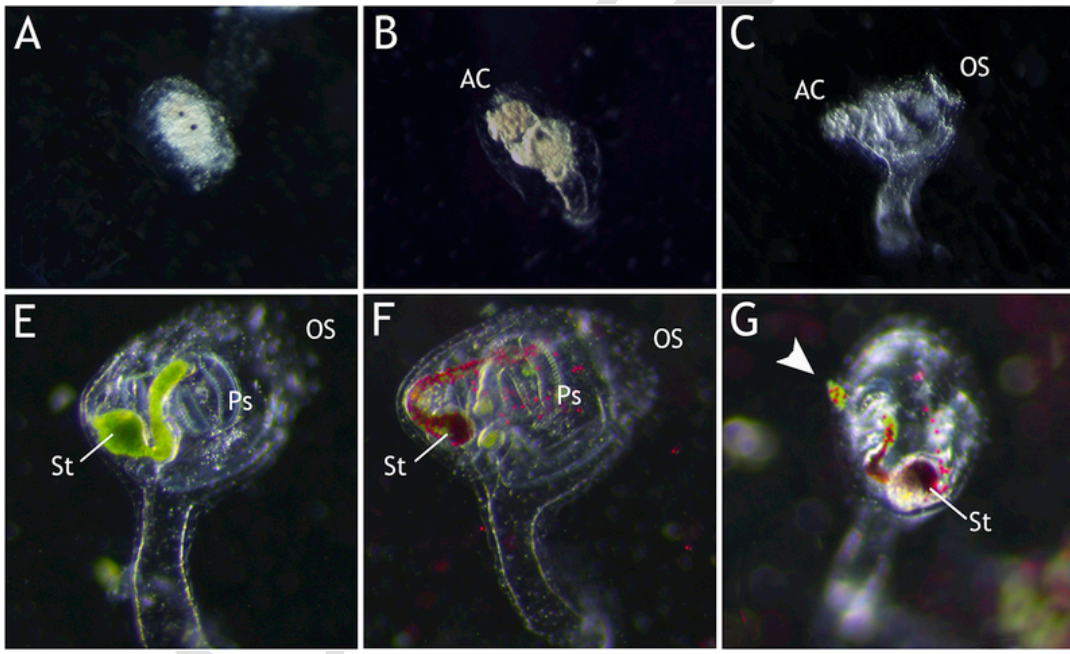

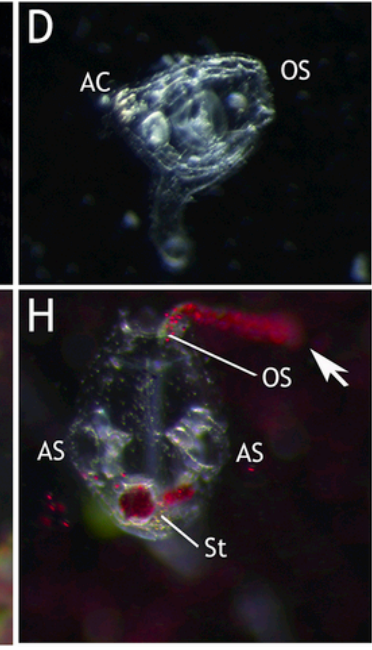

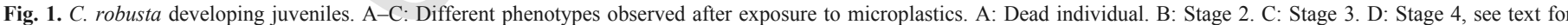

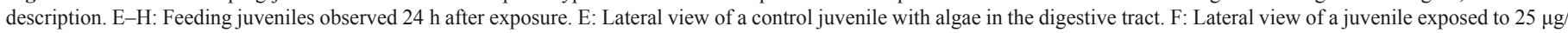

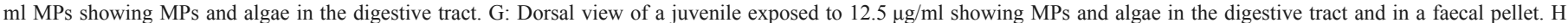

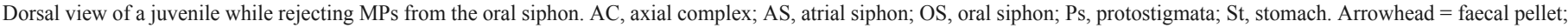
arrow $=$ rejected MPs 
tract was recorded. Feeding efficiency was calculated as: (number of fed individuals/total number of individuals scored) x 100 .

\subsection{Statistical analysis}

All data were analyzed using the software R (R-Core-Team, 2013). A single way Analysis of Variance (ANOVA) was performed, after a Cochran Test to test the homogeneity of variance. If $\mathrm{H}_{0}$ of homoscedasticity was rejected, the data were square root transformed to meet the assumptions of the analysis. If the results of ANOVA were significant $(\mathrm{P}<0.05)$, a Tukey's Post-hoc Test was performed to disentangle differences among groups.

\section{Results}

\subsection{Effects on ascidians}

\subsubsection{Development and larval survival rate}

Larval survival rate was not affected by MPs exposure at all the tested concentrations $\left(\mathrm{F}_{4,10}=2.0433 ; \mathrm{p}=0.1639\right.$; Fig. $\left.\mathrm{S} 1\right)$. Moreover, exposed larvae showed a normal phenotype, perfectly comparable to control samples (Fig. S2).

\subsubsection{Metamorphosis}

We recorded in all the experimental groups the presence of dead individuals and juveniles at different developmental stages (Fig. 1A-D). Dead animals were observed in all the experimental groups and no statistically significant difference was reported. The percentage of individuals that after 4 day reached stage 4 (Fig. 1D) was significantly lower in all the exposed groups compared to control group $\left(\mathrm{F}_{4,10}=11.388, \mathrm{p}=0.0009\right)$ (Fig. $\left.2 \mathrm{~A}\right)$. Moreover, the percentage of juveniles scored as stage 3 (Fig. 1C) was significantly higher at 12.5 and $25 \mu \mathrm{g} / \mathrm{ml}$ concentrations than in control group $\left(\mathrm{F}_{4,10}=4.6175\right.$, $\mathrm{p}=0.0226$ ) (Fig. 2A). Metamorphosis was slowed down but manifest malformations were not observed at all the tested concentrations.

\subsubsection{Juvenile survival}

No statistically significant difference in juvenile survival was observed between control and treated samples: survival rate ranged from $83.7 \%$, observed in control group and $67.5 \%$ registered at the highest MPs concentration $\left(\mathrm{F}_{4,10}=1.147 ; \mathrm{p}=0.3894\right.$; Fig. $\left.\mathrm{S} 3\right)$.

\subsubsection{Feeding behaviour and ingestion rates}

After $1 \mathrm{~min}$ of exposure at the three highest concentrations, juveniles had already MPs in their digestive tract (Fig. 2B) (Video 1). The number of styrene MPs ingested increased with particle concentration $\left(\mathrm{F}_{4,10}=40.804, \mathrm{p}=3.66^{*} 10^{-6}\right)$. In particular, the number of MPs ingested in juveniles exposed to 12.5 and $25 \mu \mathrm{g} / \mathrm{ml}$ was significantly higher than that ingested by juveniles exposed to $1.25 \mu \mathrm{g} / \mathrm{ml}$ (Fig. 2B). After $24 \mathrm{~h}$ (Fig. 1E-G, 2C), very few individuals had MPs only in the digestive and the differences were not significant for all the concentrations $\left(\mathrm{F}_{4,10}=0.7388, \mathrm{p}=0.5865\right)$. Most of the juveniles exposed to 0.125 and $1.25 \mu \mathrm{g} / \mathrm{ml}$ had no MPs or had expelled them in the faecal pellets. At the two highest concentrations (12.5 and $25 \mu \mathrm{g} / \mathrm{ml})$, a significant higher percentage of individuals displayed MPs both in the pellets and in the digestive tract $(12.5$ and $25 \mu \mathrm{g} / \mathrm{ml}$ vs the other three treatments: $\left.\mathrm{F}_{4,10}=32.217, \mathrm{p}=1.092 * 10^{-5}\right)$. Some juveniles were observed while rejecting MPs and algae from oral siphon (Fig. 1H).

Supplementary video related to this article can be found at https:// doi.org/10.1016/j.envpol.2017.11.030.
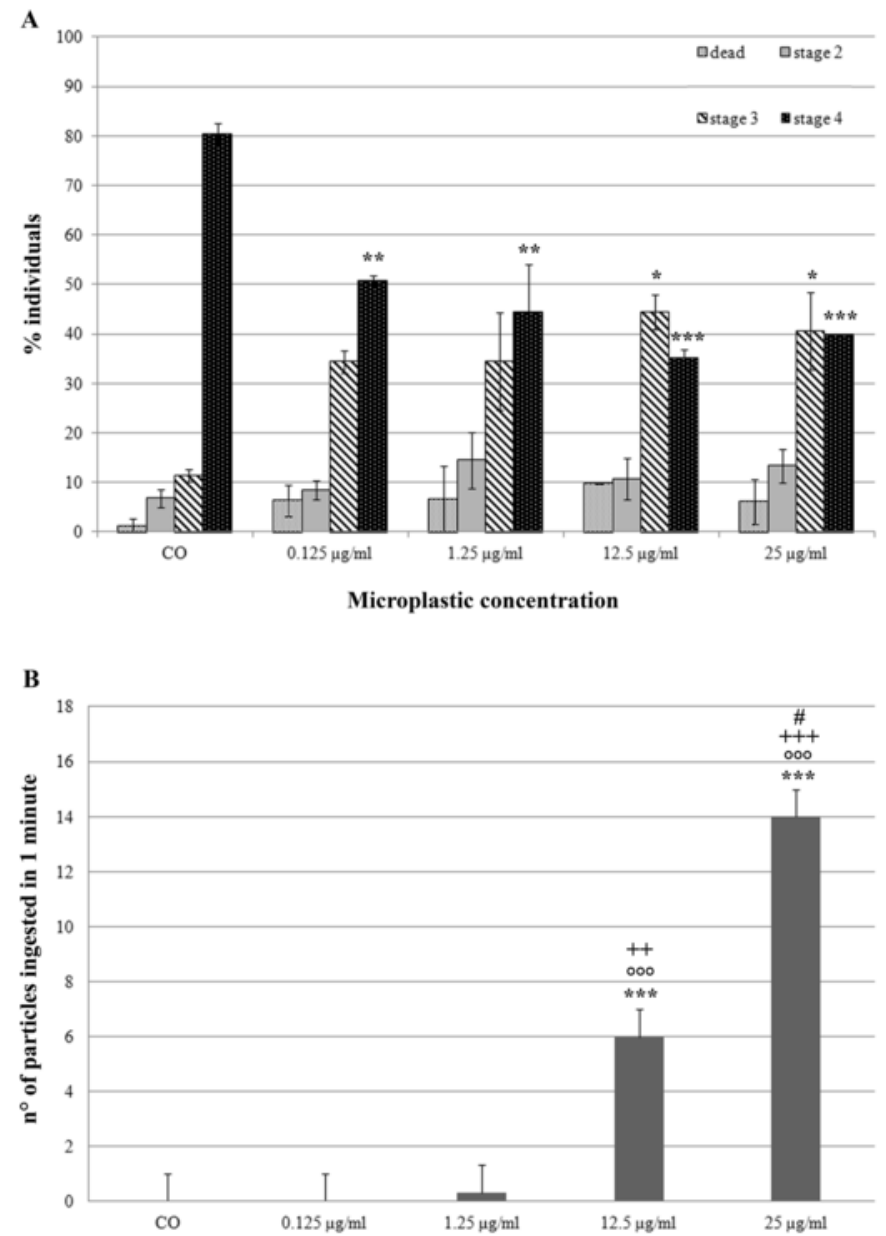

Microplastic concentration

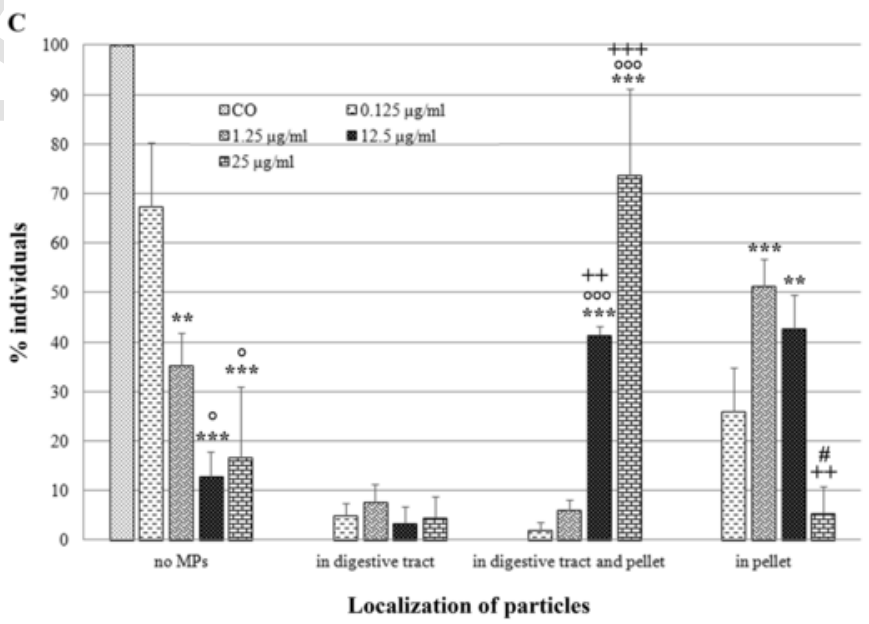

Fig. 2. Effects of polystyrene microplastics on C. robusta. Data are means of 3 replicates \pm standard error (SE). A: Percentages of juveniles at different developmental stages observed after 4-day exposure to different concentrations of MPs. B: Number of MPs ingested after $1 \mathrm{~min}$ of exposure at different concentrations. C: Localization of MPs after $24 \mathrm{~h}$ from exposure. Legend of symbols: $*=$ differences from control; ${ }^{\circ}=$ differences from $0.125 \mu \mathrm{g} / \mathrm{ml} ;+=$ differences from 1.25 ; \# = differences from $12.5 \mu \mathrm{g} / \mathrm{ml}$. The repetition of each symbol indicate the level of significance according to $\mathrm{R}$ significance codes: $\mathrm{p}<0.001 * * * ; \mathrm{p}<0.01 * * ; \mathrm{p}<0.05 *$. 

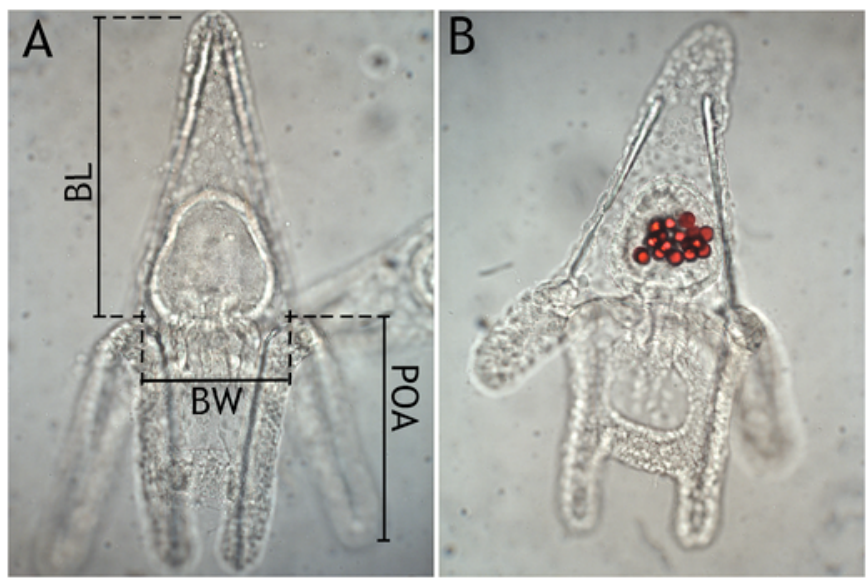

Fig. 3. Paracentrotus lividus plutei. A: Control pluteus $72 \mathrm{~h}$ post fertilization. B: Pluteus developed from an embryo exposed to $25 \mu \mathrm{g} / \mathrm{ml}$ MPs. BL: body length; BW body width POA: post oral arm.

\subsection{Effects on sea urchins}

\subsubsection{Development and larval survival rate}

Plutei can efficiently ingest MPs that can be observed in their digestive tract (Fig. 3B). After $72 \mathrm{~h}$ exposure, no difference in the survival rate was observed between control larvae and those developed in presence of MPs beads at all tested concentrations $\left(F_{4,10}=0.6298\right.$; $\mathrm{p}=0.6524)$ (Fig. S4).

Significant differences were found in body length and arm length of plutei reared at different bead concentrations (Fig. 4A-C). Plutei exposed to $12.5 \mu \mathrm{g} / \mathrm{ml}$ were significantly longer than control ones $\left(\mathrm{F}_{4,445}=20.24, \mathrm{p}<0.0001\right.$; Tukey's post hoc test $\left.\mathrm{p}=0.0001\right)$, while plutei exposed to $25 \mu \mathrm{g} / \mathrm{ml}$ were shorter $\left(\mathrm{F}_{4,445}=20.24, \mathrm{p}<0.0001\right.$; Tukey's post hoc test $\mathrm{p}=0.0002$ ). Differences in body width were found between control group and $0.125 \mu \mathrm{g} / \mathrm{ml}$, between $0.125 \mu \mathrm{g} / \mathrm{ml}$ and all the other treatments and between $12.5 \mu \mathrm{g} / \mathrm{ml}$ and $25 \mu \mathrm{g} / \mathrm{ml}$ $\left(\mathrm{F}_{4,445}=18.29, \mathrm{p}<0.005\right)$. At last, treated plutei had longer arms than control group when developed at 0.125 and $12.5 \mu \mathrm{g} / \mathrm{ml}\left(\mathrm{F}_{4,445}=39.67\right.$, $\mathrm{p}<0.0001$; Tukey's post hoc test $\mathrm{p}<0.0001)$. Plutei developed at $1.25 \mu \mathrm{g} / \mathrm{ml}$ had shorter arms compared to $0.125 \mu \mathrm{g} / \mathrm{ml}$ (Tukey's post hoc test $\mathrm{p}=0.0336$ ) and those developed at $25 \mu \mathrm{g} / \mathrm{ml}$ had shorter arms compared to all the other treatments (Tukey's post hoc test $\mathrm{p}<0.0001)$.

\subsection{Comparison between ascidian and sea urchin feeding efficiency}

After $1 \mathrm{~h}$ exposure to MPs, both ascidian juveniles and plutei ingested beads at all tested concentrations but they displayed different efficiencies. In both species, the percentage of individuals with beads in their digestive tract increased with MP concentration. At $1.25,12.5$ and $25 \mu \mathrm{g} / \mathrm{ml}$, more than $87 \%$ of ascidian juveniles had MPs in their digestive tract. These values were significantly higher than the percentage of juveniles that ingested MPs at $0.125 \mu \mathrm{g} / \mathrm{ml}$ concentration and in control group $\left(\mathrm{F}_{4,10}=106.1, \mathrm{p}=3.08 * 10^{-8}\right)$ (Fig. 5). Only $20 \%$ of plutei had ingested MPs at $0.125 \mu \mathrm{g} / \mathrm{ml}$, while $100 \%$ of plutei at $25 \mu \mathrm{g} / \mathrm{ml}$ had them in the digestive tract $\left(\mathrm{F}_{4,10}=283.55\right.$, $\mathrm{p}<0.0001)$. At highest concentrations, there is not a significant difference in the efficiency of ingestion between the two species, as almost all individuals fed on MPs (ANOVA: $12.5 \mu \mathrm{g} / \mathrm{ml}: \mathrm{F}_{1,4}=0.4895$ $\left.\mathrm{p}=0.5227 ; 25 \mu \mathrm{g} / \mathrm{ml} \mathrm{F}_{1,4}=1 \mathrm{p}=0.3739\right)$. On the other hand, at the
A

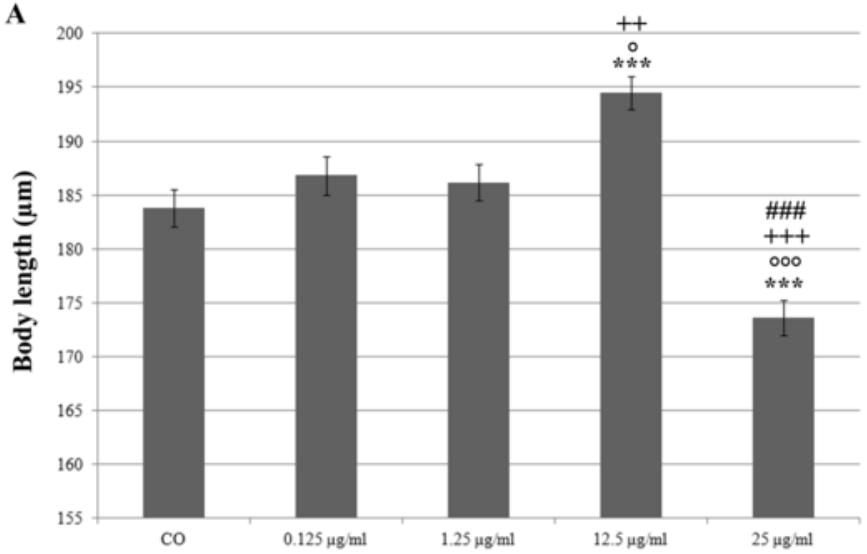

Microplastic concentration

B

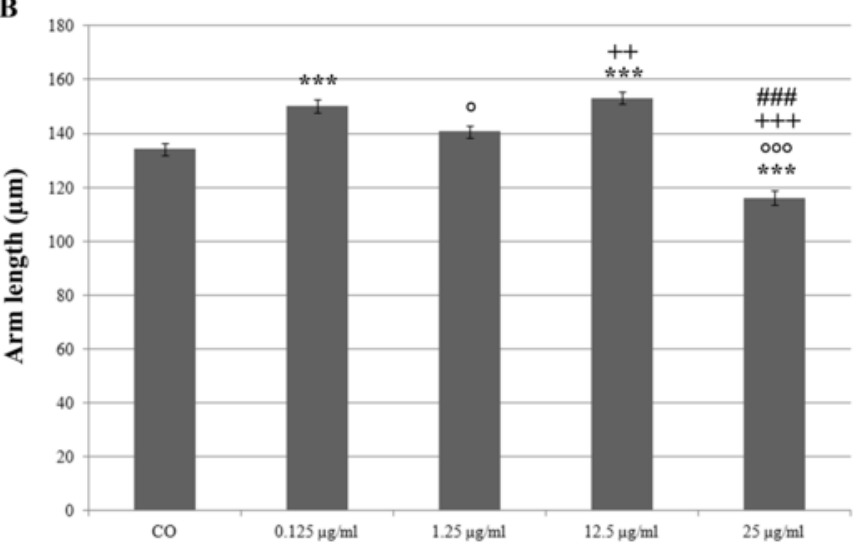

Microplastic concentration

C

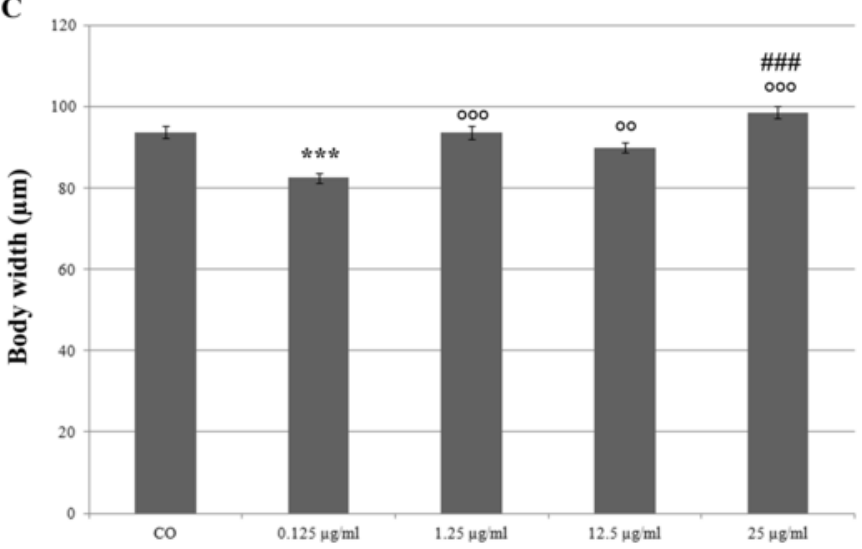

Microplastic concentration

Fig. 4. Morphometric analysis of plutei exposed to MPs. Legend of symbols: $*=$ differences from control; ${ }^{\circ}=$ differences from $0.125 \mu \mathrm{g} / \mathrm{ml} ;+=$ differences from 1.25 ; \# = differences from $12.5 \mu \mathrm{g} / \mathrm{ml}$. The repetition of each symbol indicates the level of significance according to R significance codes: $\mathrm{p}<0.001 * * * ; \mathrm{p}<0.01 * * ; \mathrm{p}<0.05 *$.

lowest concentrations, the efficiency of ingestion of planktonic plutei resulted significantly lower than that of filter-feeding benthic juveniles of C. robusta (ANOVA: $0.125 \mu \mathrm{g} / \mathrm{ml}: \mathrm{F}_{1,4}=7.9014 \mathrm{p}=0.04827$; $\left.1.25 \mu \mathrm{g} / \mathrm{ml}: \mathrm{F}_{1,4}=27.888 \mathrm{p}=0.006166\right)$ (Fig. 5). 


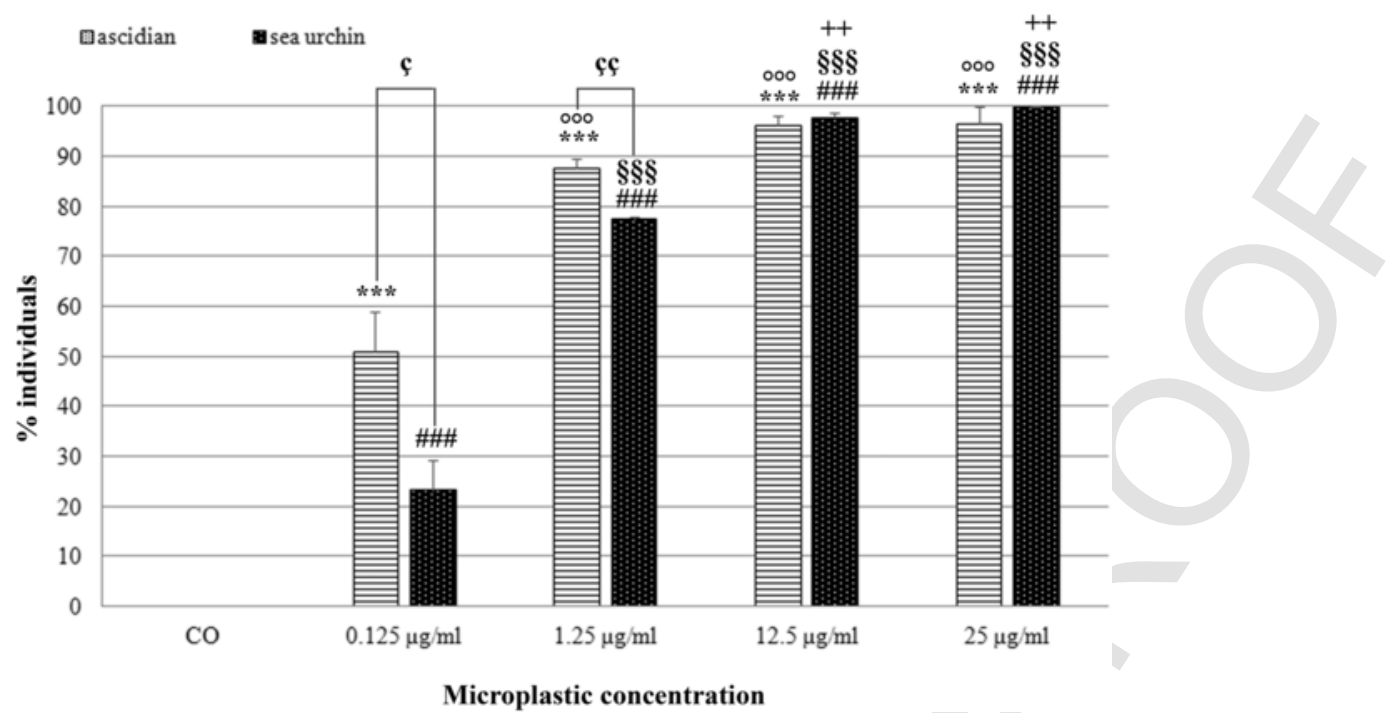

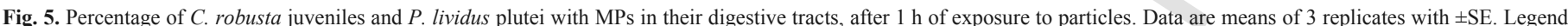

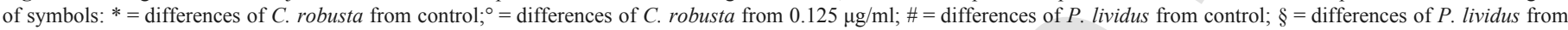

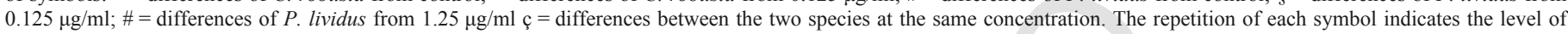
significance according to R significance codes: $\mathrm{p}<0.001 * * * ; \mathrm{p}<0.01 * * ; \mathrm{p}<0.05 *$.

\section{Discussion}

Plastic pollution represents one of the main threats to aquatic ecosystems: the high production level and the slow degrading time of plastic have led to an increasing amount of plastic-derived debris in oceans and seas. After degradation, these remains are fragmented into micro sized particles that can be ingested by marine organisms and enter the food web (Andrady, 2015).

In this study, we evaluated the effects of polystyrene MPs on the development of two ecologically relevant marine invertebrates: the ascidian $C$. robusta and the sea urchin $P$. lividus. Our results add new important information about the effects of this emerging pollutant on early life stages of invertebrates with different feeding strategies.

As already reported for many other taxa, the feeding stages of both the analyzed species are able to efficiently ingest MPs. In particular, ascidian juveniles and plutei were fed with a suspension of MPs and algae and they appeared not to be able to discriminate between food and inorganic particles, as other invertebrates proved to do (Fernández, 1979; Paffenhofer and Vansant, 1985). Indeed, when ascidian juveniles are exposed to high particles concentrations, the MPs ingestion occurred as soon as beads were added to ASWH, suggesting that juveniles, filtering the water, did not make any kind of selection. However, some individuals were observed rejecting microbeads and algae from the oral siphon, with a series of whole body contractions. This is probably a reflex triggered by sensorial organs upon siphon tentacles (Mackie et al., 2006; Rigon et al., 2013) and due to the excessive intake of particles. In contrast, nauplii of the copepod Calanus pacificus strongly selected and consumed almost exclusively algal cells, when fed with mixtures of planktonic algae and plastic beads of different or similar sizes (Fernández, 1979). The ability of $C$. pacificus to select organic particles could be due to the restrictive diet of naupilii that feed only upon plant material (Fernández, 1979), while ascidian juveniles filter water uptaking any kind of particles. Thus, the different sensitiveness to MPs observed in these two animals could be related to their specific feeding behaviour. Furthermore, the disappearance of the rejection reflex in Ciona juveniles at high MPs concentration was probably caused by an adaptive behav- iour of the sensorial organs. Indeed, different sensory structures have been described in ascidian siphons. In the atrial cavity, mechanoreceptors, the cupular organs, send their axons to the central nervous system. At the oral siphon base, the coronal organ, consisting of secondary neurons, borders the velum and tentacles. In addition, scattered sensory cells are located in siphons inner and outer wall (Mackie et al., 2006; Rigon et al., 2013).

Previous works reported that numerous marine organisms are able to ingest and expel plastic microspheres without any apparent negative effects (Thompson et al., 2004). On the contrary, our results suggested that MPs effects depend on animal feeding strategy and life stages.

After an hour of exposure, a significant percentage of ascidian juveniles and plutei showed plastic beads in their stomach at all tested concentrations. However, comparing MPs uptake in the two animal models, the higher ingestion ability of the filter-feeding juveniles appeared evident. Although at the two highest concentrations almost all individuals had ingested MPs, regardless of the species, at the lowest concentrations a significant higher percentage of ascidian juveniles ate microbeads compared to sea urchin plutei. This result suggested that the presence of MPs in the environment, even at low concentrations, can impact sessile filtering organisms more than pelagic suspension feeders. This consideration is strengthened by the fact that juvenile and adult ascidians employ the pharyngeal basket to filter a huge amount of water per day, estimated around $46.4 \mathrm{ml} / \mathrm{min}$ for adults with a total dry weight of $0.84 \mathrm{~g}$ (Randløv and Riisgård, 1979).

After $24 \mathrm{~h}$, almost all ascidian juveniles, that ingested MPs at the concentrations of $0.125 \mu \mathrm{g} / \mathrm{ml}$ and $1.25 \mu \mathrm{g} / \mathrm{ml}$, managed to expel them with faecal pellets. However, with the increase of particle concentration and, therefore of ingestion, it became more difficult for animals to expel them as demonstrated by the higher percentage of individuals that even after pellet expulsion retained particles in their stomach. Moreover, at the highest concentrations, some ascidian juveniles tried to expel their stomach content by rejecting it from the oral siphon, with a series of contractions of the whole body. Also this behaviour was not completely efficient to eliminate MPs from the digestive tract, suggesting that a higher particles intake can determine a higher risk of damages and digestive system block. 
Studies on MPs effects on animal development are particularly scarce, even if different stages of life cycle can have diverse sensitiveness, being the larvae usually the most vulnerable one. Thus, we explored the impact of MPs presence on the early life stages of ascidians and sea urchin. Although MPs exposure did not affect the survival rate of $C$. robusta juveniles and $P$. lividus embryos, plastic beads appeared to be detrimental during some developmental phases.

We analyzed three different standard parameters to characterized MPs effects on plutei body growth and we observed values that significantly differed from control group. A clear trend was not observable: the absence of a dose-dependent effect between bead concentrations and measured parameters is not unusual in aquatic organisms, being already reported in other species of sea urchin (Kaposi et al., 2013), copepods (Cole et al., 2013) and marine worms (Wright et al., 2013). In our case, the reduction of body and arm length and the increase of body width reported in plutei exposed to $25 \mu \mathrm{g} / \mathrm{ml}$ highlight that the co-ingestion of beads and algae compromised the correct development of the body shape. More controversial results are the increase of body length at $12.5 \mu \mathrm{g} / \mathrm{ml}$, the increase of arm length at 0.125 and $12.5 \mu \mathrm{g} /$ $\mathrm{ml}$ and the reduction of body width at $0.125 \mu \mathrm{g} / \mathrm{ml}$. The high variability in particles uptake and release occurring at the lower tested concentrations may be responsible for the variability of the measured responses. In contrast, at the highest tested concentration, MPs distribution was probably more homogenous making the exposure more uniform and the effects more consistent. Moreover, the same kind of results have been found for the echinoderm species Tripneustes gratilla in which a reduction of body width was observed at the lowest and highest concentration tested but not at the intermediate ones (Kaposi et al., 2013).

In Ciona, the metamorphosis proved to be the most sensitive process to MPs presence. Exposed juveniles showed a significant slowdown of metamorphosis, displaying a high percentage of individual at an earlier developmental stage than controls. Since MPs did not affect the embryonic development of the non-feeding ascidian larvae, we supposed that the effects observed on the other stages were mainly due to the physical presence of the beads rather than to chemical released by plastic degradation.

It was proposed that the physical presence of microbeads can alter the development of a planktotrophic larva, probably reducing the food intake: in copepods, MPs presence appeared to decrease food ingestion (Cole et al., 2013), eventually leading to fertility reduction (Lee et al., 2013). Moreover, it was suggested that the selective feeding behaviour of $C$. pacificus nauplii could be an energy input optimization, so the animals could achieve a larger input of energy per unit time than would be if no selection occurred (Fernández, 1979). Thus, the non-selection behaviour displayed by ascidian juveniles and plutei suggested that MPs ingestion can cause a reduction of nutritional uptake, responsible for the developmental and growth alterations observed in ascidians and plutei.

These considerations suggested that sensitiveness to MPs differ among species, indicating the necessity to extend the studies to a wider range of species in order to elucidate MPs impact on marine ecosystem.

\section{Conclusion}

According to our results, the developing stages of both ascidian and sea urchin are able to ingest MPs. Particularly, comparing the intake efficiency of the two species, the sessile filtering organisms appeared more vulnerable to MPs effects than pelagic suspension feeders. Even if MPs exposure do not seem to influence specimens survival, their development was affected as plastic beads ingestion slowed down metamorphosis of $C$. robusta and altered post-embryonic development or/and growth of $P$. lividus. These results appear particularly worrying when we consider that the ability to clear the gut of plastic decreases with the increase of MPs concentration. In long-term exposure, this could cause MPs accumulation in the digestive tract, definitively compromise the nutritional uptake and ultimately lead to the animal death. Thus, our results are particularly relevant as they revealed that developmental stages of different species are highly sensitive to MPs presence, prompting the necessity to monitor coastal invertebrate populations since MPs can alter generation recruitment.

\section{Acknowledgements}

This research did not receive any specific grant from funding agencies in the public, commercial, or not-for-profit sectors. The authors are grateful to: Prof. L. Manni and Dr. F. Gasparini that provided adult specimens of Ciona robusta; the scuba divers of Biosciences Department that collected Paracentrotus lividus specimens and Julia Yap for English revision.

\section{Appendix A. Supplementary data}

Supplementary data related to this article can be found at https:// doi.org/10.1016/j.envpol.2017.11.030.

\section{References}

Andrady, A.L., 2015. Persistence of Plastic Litter in the Oceans, in: Marine Anthropogenic Litter. Springer, 57-72.

Barnes, D.K.a, Galgani, F., Thompson, R.C., Barlaz, M., 2009. Accumulation and fragmentation of plastic debris in global environments. Philos. Trans. R. Soc. Lond. B. Biol. Sci. 364, 1985-1998. https://doi.org/10.1098/rstb.2008.0205.

Boerger, C.M., Lattin, G.L., Moore, S.L., Moore, C.J., 2010. Plastic ingestion by planktivorous fishes in the North pacific central gyre. Mar. Pollut. Bull. 60, 2275-2278.

Browne, M.A., Crump, P., Niven, S.J., Teuten, E., Tonkin, A., Galloway, T., Thompson, R., 2011. Accumulation of microplastic on shorelines woldwide: sources and sinks. Environ. Sci. Technol. 45, 9175-9179.

Browne, M.A., Dissanayake, A., Galloway, T.S., Lowe, D.M., Thompson, R.C., 2008. Ingested microscopic plastic translocates to the circulatory system of the mussel, Mytilus edulis (L.). Environ. Sci. Technol. 42, 5026-5031. https://doi.org/10.1021/ es800249a, CCC: $\$ 40.75$.

Brunetti, R., Gissi, C., Pennati, R., Caicci, F., Gasparini, F., Manni, L., 2015. Morphological evidence that the molecularly determined Ciona intestinalis type A and type B are different species: Ciona robusta and Ciona intestinalis. J. Zool. Syst. Evol. Res. 53, 186-193. https://doi.org/10.1111/jzs.12101.

Burighel, P., Cloney, R.A., 1997. Urochordata: ascidiacea. Hemichordata, Chaetognata, and the Invertebrate Chordates Harrison, F.W., Ruppert, E.E. (Eds.), Microscopic Anatomy of Invertebrates. vol. 15, Wiley-Liss, New York, pp. 221-347.

Carpenter, E.J., Anderson, S.J., Harvey, G.R., Miklas, H.P., Peck, B., 1972. Polystyrene spherules in coastal waters. Sci. (80-. ) 178, 749-750.

Chiba, S., Sasaki, A., Nakayama, A., Takamura, K., Satoh, N., 2004. Development of Ciona intestinalis juveniles (through 2nd ascidian stage). Zool. Sci. 21, 285-298. https://doi.org/10.2108/zsj.21.285.

Cohen, J.T., Carlson, G., Charnley, G., Coggon, D., Delzell, E., Graham, J.D., Greim, H., Krewski, D., Medinsky, M., Monson, R., Paustenbach, D., Petersen, B., Rappaport, S., Rhomberg, L., Ryan, P.B., Thompson, K., 2002. A comprehensive evaluation of the potential health risks associated with occupational and environmental exposure to styrene. J. Toxicol. Environ. Heal. Part B 5, 1-263. https://doi.org/10. 1080/10937400252972162.

Cole, M., Lindeque, P., Fileman, E., Halsband, C., Goodhead, R., Moger, J., Galloway, T.S., 2013. Microplastics ingestion by zooplankton. Environ. Sci. Technol. 47, 6646-6655. https://doi.org/10.1021/es400663f.

Cole, M., Lindeque, P., Halsband, C., Galloway, T.S., 2011. Microplastics as contaminants in the marine environment: a review. Mar. Pollut. Bull. 62, 2588-2597. https://doi.org/10.1016/j.marpolbul.2011.09.025.

Colton, J.B., Knapp, F.D., Burns, B.R., 1974. Plastic particles in surface waters of the Northwestern Atlantic. Sci. (80-. ) 185, 842-852.

Davidson, T.M., 2012. Boring crustaceans damage polystyrene floats under docks polluting marine waters with microplastic. Mar. Pollut. Bull. 64, 1821-1828. https:// doi.org/10.1016/j.marpolbul.2012.06.005. 
Davison, P., Asch, R.G., 2011. Plastic ingestion by mesopelagic fishes in the North pacific subtropical gyre. Mar. Ecol. Prog. Ser. 432, 173-180.

Derraik, J.G., 2002. The pollution of the marine environment by plastic debris: a review. Mar. Pollut. Bull. 44, 842-852. https://doi.org/10.1016/ S0025-326X(02)00220-5.

Doyle, M.J., Watson, W., Bowlin, N.M., Sheavly, S.B., 2011. Plastic particles in coastal pelagic ecosystems of the Northeast Pacific ocean. Mar. Environ. Res. 71, $41-52$.

Eriksen, M., Lebreton, L.C.M., Carson, H.S., Thiel, M., Moore, C.J., Borerro, J.C., Galgani, F., Ryan, P.G., Reisser, J., 2014. Plastic pollution in the world 's Oceans: more than 5 trillion plastic pieces weighing over 250, 000 tons afloat at sea. PLoS One 9, 1-15. https://doi.org/10.1371/journal.pone.0111913.

Eriksen, M., Mason, S., Wilson, S., Box, C., Zellers, A., Edwards, W., Farley, H., Amato, S., 2013. Microplastic pollution in the surface waters of the laurentian Great Lakes. Mar. Pollut. Bull. 77, 177-182. https://doi.org/10.1016/j.marpolbul.2013. 10.007 .

Fendall, L.S., Sewell, M.A., 2009. Contributing to marine pollution by washing your face: microplastics in facial cleansers. Mar. Pollut. Bull. 58, 1225-1228.

Fernández, F., 1979. Particle selection in the nauplius of Calanus pacificus. J. Plankton Res. 1, 313-328.

Gandara e Silva, P.P., Nobre, C.R., Resaffe, P., Pereira, C.D.S., Gusmão, F., 2016. Leachate from microplastics impairs larval development in brown mussels. Water Res. 106, 364-370. https://doi.org/10.1016/j.watres.2016.10.016.

Giudice, G., 1986. Embryonic morphogenesis. In: The Sea Urchin Embryo. Springer, Berlin Heidelberg, pp. 37-72.

Hotta, K., Mitsuhara, K., Takahashi, H., Inaba, K., Oka, K., Gojobori, T., Ikeo, K. 2007. A web-based interactive developmental table for the ascidian Ciona intestinalis, including 3D real-image embryo reconstructions: I. From fertilized egg to hatching larva. Dev. Dyn. 236, 1790-1805. https://doi.org/10.1002/dvdy.21188.

Imhof, H.K., Ivleva, N.P., Schmid, J., Niessner, R., Laforsch, C., 2013. Contamination of beach sediments of a subalpine lake with microplastic particles. Curr. Biol. 23, R867-R868. https://doi.org/10.1016/j.cub.2013.09.001.

Kaposi, K.L., Mos, B., Kelaher, B.P., Dworjanyn, S.A., 2013. Ingestion of microplastic has limited impact on a marine larva. Environ. Sci. Technol. 48, 1638-1645. https://doi.org/10.1021/es404295e.

Laist, D.W., 1997. Impacts of marine debris: entanglement of marine life in marine debris including a comprehensive list of species with entanglement and ingestion records. In: Marine Debris: Sources, Impacts and Solutions. Springer, Berlin, Germany, pp. 99-141. https://doi.org/10.1007/978-1-4613-8486-1.

Lambert, C.C., Brandt, C.L., 1967. The effect of light on the spawning of Ciona intestinalis. Biol. Bull. 132, 222-228.

Lawrence, J., 1975. On the relationship between marine plants and sea urchins. Oceanogr. Mar. Biol. Annu. Rev. 13, 213-286.

Lee, K., Shim, W.J., Kwon, O.Y., Kang, J., 2013. Size-dependent Effects of micro polystyrene particles in the marine copepod Tigriopus japonicus. Environ. Sci Technol. 47, 11278-11283. https://doi.org/10.1021/es401932b.

Lonnstedt, O.M., Eklov, P., 2016. Environmentally relevant concentrations of microplastic particles influence larval fish ecology. Sci. (80-. ) 352, 1213-1216. https://doi.org/10.1126/science.aad8828.

Lusher, A., McHugh, M., Thompson, R., 2012. Occurrence of microplastics in the gastrointestinal tract of pelagic and demersal fish from the English Channel. Mar. Pollut. Bull. 67, 94-99.

Mackie, G.O., Burighel, P., Caicci, F., Manni, L., 2006. Innervation of ascidian siphons and responses to stimulation. Can. J. Zoology 84, 1146-1162.

Mato, Y., Isobe, T., Takada, H., Kanehiro, H., Ohtake, C., Kaminuma, T., 2001. Plastic resin pellets as a transport medium for toxic chemicals in the marine environment. Environ. Sci. Technol. 35, 318-324. https://doi.org/10.1021/es0010498.

Mercurio, S., Di Benedetto, C., Sugni, M., Candia Carnevali, M.D., 2014. Primary cell cultures from sea urchin ovaries: a new experimental tool. Vitr. Cell. Dev. Biol. Anim. 50, 139-145. https://doi.org/10.1007/s11626-013-9686-1.

Murray, F., Cowie, P.R., 2011. Plastic contamination in the decapod crustacean Nephrops norvegicus (Linnaeus, 1758). Mar. Pollut. Bull. 62, 1207-1217. https:// doi.org/10.1016/j.marpolbul.2011.03.032
Nobre, C.R., Santana, M.F.M., Maluf, A., Cortez, F.S., Cesar, A., Pereira, C.D.S., Turra, A., 2015. Assessment of microplastic toxicity to embryonic development of the sea urchin Lytechinus variegatus (Echinodermata: Echinoidea). Mar. Pollut. Bull. 92, 99-104. https://doi.org/10.1016/j.marpolbul.2014.12.050.

Noren, F., Naustvoll, F., 2010. Survey of Microscopic Anthropogenic Particles in Skagerrak.

O'Brine, T., Thompson, R.C., 2010. Degradation of plastic carrier bags in the marine environment. Mar. Pollut. Bull. 60, 2279-2283. https://doi.org/10.1016/j. marpolbul.2010.08.005.

Oehlmann, J., Schulte-Oehlmann, U., Kloas, W., Jagnytsch, O., Lutz, I., Kusk, K.O., Wollenberger, L., Santos, E.M., Paull, G.C., Van Look, K.J.W., Tyler, C.R., 2009. A critical analysis of the biological impacts of plasticizers on wildlife. Philos. Trans. R. Soc. B Biol. Sci. 364, 2047-2062. https://doi.org/10.1098/rstb.2008. 0242

Paffenhofer, G.A., Vansant, K.B., 1985. The feeding response of a marine planktonic copepod to quantity and quality of particles. Mar. Ecol. Prog. Ser. 27, 55-65.

Pennati, R., Ficetola, G.F., Brunetti, R., Caicci, F., Gasparini, F., Griggio, F., Sato, A., Stach, T., Kaul-Strehlow, S., Gissi, C., Manni, L., 2015. Morphological differences between larvae of the Ciona intestinalis species complex: hints for a valid taxonomic definition of distinct species. PLoS One 10, e0122879. https://doi.org/ 10.1371/journal.pone. 0122879

R-Core-Team, 2013. R: a language and environment for statistical computing.

Randløv, A., Riisgård, H.U., 1979. Efficiency of particle retention and filtration rate in four species of ascidians. Mar. Ecol. Prog. Ser. 55-59.

Rigon, F., Stach, T., Caicci, F., Gasparini, F., Burighel, P., Manni, L., 2013. Evolutionary diversification of secondary mechanoreceptor cells in Tunicata. BMC Evol. Biol. 13, 112-118.

Satoh, N., 1994. Developmental Biology of Ascidians. Cambridge University Press, New York.

Stefatos, A., Charalampakis, M., Papatheodorou, G., Ferentinos, G., 1999. Marine debris on the seafloor of the Mediterranean Sea: examples from two enclosed gulfs in western Greece. Mar. Pollut. Bull. 36, 389-393.

Strathmann, R.R., 1971. The feeding behaviour of planktotrophic echinoderm larvae: mechanisms, regulation, and rates of suspension-feeding. J. Exp. Mar. Biol. Ecol. 6, 109-160.

Talsness, C.E., Andrade, A.J.M., Kuriyama, S.N., Taylor, J.a, vom Saal, F.S., 2009. Components of plastic: experimental studies in animals and relevance for human health. Philos. Trans. R. Soc. Lond. B. Biol. Sci. 364, 2079-2096. https://doi.org/ 10.1098/rstb.2008.0281.

Teuten, E.L., Saquing, J.M., Knappe, D.R.U., Barlaz, M.A., Jonsson, S., Björn, A. Rowland, S.J., Thompson, R.C., Galloway, T.S., Yamashita, R., Ochi, D., Watanuki, Y., Moore, C., Viet, P.H., Tana, T.S., Prudente, M., Boonyatumanond, R., Zakaria, M.P., Akkhavong, K., Ogata, Y., Hirai, H., Iwasa, S., Mizukawa, K., Hagino, Y., Imamura, A., Saha, M., Takada, H., 2009. Transport and release of chemicals from plastics to the environment and to wildlife. Philos. Trans. R. Soc. B 364, 2027-2045. https://doi.org/10.1098/rstb.2008.0284.

Thompson, R.C., Olsen, Y., Mitchell, R.P., Davis, A., Rowland, S.J., John, A.W.G., McGonigle, D., Russell, A.E., 2004. Lost at sea: where is all the plastic?. Sci. (80) 304, 838-838.

van Franeker, J.A., Blaize, C., Danielsen, J., Fairclough, K., Gollan, J., Guse, N., Hansen, P.-L., Heubeck, M., Jensen, J.-K., Le Guillou, G., Olsen, B., Olsen, K.-O. Pedersen, J., Stienen, E.W.M., Turner, D.M., 2011. Monitoring plastic ingestion by the northern fulmar Fulmarus glacialis in the North Sea. Environ. Pollut. 159, 2609-2615.

Wright, S.L., Rowe, D., Thompson, R.C., Galloway, T.S., 2013. Microplastic ingestion decreases energy reserves in marine worms. Curr. Biol. 23, R1031-R1033. https:// doi.org/10.1016/j.cub.2013.10.068.

Zega, G., Pennati, R., Candiani, S., Pestarino, M., De Bernardi, F., 2009. Solitary ascidians embryos (Chordata, Tunicata) as model organisms for testing coastal pollutant toxicity. Invertebr. Surviv. J. 6, S29-S34. 